\title{
The Ovarian Transcriptome of Reproductively Aged Multiparous Mice: Candidate Genes for Ovarian Cancer Protection ${ }^{+}$
}

\author{
Ulises Urzúa ${ }^{1, * \mathbb{D}}$, Carlos Chacón ${ }^{1}$, Maximiliano Norambuena ${ }^{1}$, Luis Lizama ${ }^{2}$, \\ Sebastián Sarmiento ${ }^{1}$, Esther Asaki ${ }^{3}{ }^{10}$, John I Powell ${ }^{3}$ and Sandra Ampuero ${ }^{2}$ \\ 1 Laboratorio de Genómica Aplicada, Departamento de Oncología Básico-Clínica, Facultad de Medicina, \\ Universidad de Chile, Santiago 8380453, Chile; chacon.biotec@gmail.com (C.C.); \\ mnorambuenaa@gmail.com (M.N.); s.sarmientogodoy@gmail.com (S.S.) \\ 2 Programa de Virología, ICBM, Facultad de Medicina, Universidad de Chile, Santiago 8380453, Chile; \\ luislizama@med.uchile.cl (L.L.); sampuero@u.uchile.cl (S.A.) \\ 3 Center for Information Technology, National Institutes of Health, Bethesda, MD 20892, USA; \\ easaki@mail.nih.gov (E.A.); jip@helix.nih.gov (J.I.P.) \\ * Correspondence: uurzua@uchile.cl; Tel.: +56-229786877 \\ + This article is dedicated to the memory of Dr. David J. Munroe.
}

Received: 22 October 2019; Accepted: 30 December 2019; Published: 9 January 2020

\begin{abstract}
In middle-aged women, the decline of ovarian follicle reserve below a critical threshold marks menopause, leading to hormonal, inflammatory, and metabolic changes linked to disease. The highest incidence and mortality of sporadic ovarian cancer (OC) occur at post-menopause, while OC risk is reduced by full-term pregnancies during former fertile life. Herein, we investigate how parity history modulates the ovarian transcriptome related to such declining follicle pool and systemic inflammation in reproductively-aged mice. Female C57BL/6 mice were housed under multiparous and virgin (nulliparous) breeding regimens from adulthood until estropause. The ovaries were then subjected to follicle count and transcriptional profiling, while a cytokine panel was determined in the sera. As expected, the follicle number was markedly decreased just by aging. Importantly, a significantly higher count of primordial and total follicles was observed in aged multiparous relative to aged virgin ovaries. Consistently, among the 65 genes of higher expression in aged multiparous ovaries, 27 showed a follicle count-like pattern, 21 had traceable evidence of roles in follicular/oocyte homeostasis, and 7 were transforming-growth factor beta (TGF- $\beta$ )/bone morphogenetic protein (BMP) superfamily members. The remaining genes were enriched in cell chemotaxis and innate-immunity, and resembled the profiles of circulating CXCL1, CXCL2, CXCL5, CSF3, and CCL3, chemokines detected at higher levels in aged multiparous mice. We conclude that multiparity during reproductive life promotes the retention of follicle remnants while improving local (ovarian) and systemic immune-innate surveillance in aged female mice. These findings could underlie the mechanisms by which pregnancy promotes the long-term reduced OC risk observed at post-menopause.
\end{abstract}

Keywords: age; parity; ovary; transcriptome; follicle; inflammation; mouse model

\section{Introduction}

Aging is characterized by a wide range of cumulative damage that affects tissue homeostasis, thus predisposing to disease initiation. Cell signaling and metabolism, antioxidant defense, epigenetic status, intercellular communication, and genome stability, among other functions, become significantly impaired [1]. In the mammalian ovary, such age-related decline is largely governed 
by a sustained decrease of the quantity and quality of the oocyte pool enclosed in the ovarian follicles at different stages of maturation. Follicle depletion in women leads to a dysregulation of the hypothalamic-pituitary-gonadal axis culminating at menopause, a hallmark of women's reproduction characterized by major systemic endocrine, metabolic, and inflammatory changes [2].

Increased rates of chronic diseases, including several types of cancer, are observed in menopause. The declining follicle number has been recently proposed to play a role in ovarian cancer (OC) etiology by promoting a pre-neoplastic phenotype of the ovarian surface epithelium (OSE) [3-5], a cell layer claimed to be the origin of the most frequent OC variant, the epithelial OC [6]. According to this idea, once the ovary is depleted of follicles, OSE would be released of a proliferative blockade maintained by a paracrine factor from follicular granulosa cells [7]. An additional genetic lesion in a cancer driver gene would be necessary in order to initiate ovarian carcinogenesis [8]. The post-menopausal ovary develops several age-related morphological alterations, such as stromal fibrosis, vascular remodeling, OSE invaginations, and epithelial inclusion cysts, the latter regarded as pre-neoplastic lesions $[9,10]$. Consistent with these changes, $\mathrm{OC}$ incidence and mortality steadily increase with age, reaching a maximum during the peri-menopause and early post-menopause periods [11]. Most of the observed menopause manifestations synergize with the age-dependent systemic low-grade inflammation underlying the development of chronic diseases, including OC [12].

Equally important, the observed OC risk at menopause is significantly decreased by reproductive history during the previous fertile life. Conditions characterized by a reduced number of ovulatory events, namely parity and the use of oral contraceptives, have been recognized to reduce OC risk in various populations [11]. The underlying basis of this low-risk effect would be a decreased tear-repair, ovulatory damage to the OSE during fertile life [6]. However, despite the proposed role of follicle depletion in OC pathogenesis [3-5], much less attention has been paid to how parity and oral contraceptives might affect the number of follicles remaining at menopause, which is around 1000 non-growing follicles in women [13]. To date, just a single study has linked parity to a higher ovarian reserve in women of reproductive age [14].

Mouse models have been used to study OC risk factors, including obesity [15], inflammation [16], age [8], and genetic inheritance [17], among others. Continuing the recent work on peritoneal tumor spread and systemic inflammation in an aged syngeneic female C57BL/6 mouse model of OC maintained in multiparous and nulliparous regimens [18], here, we studied the effect of parity history on the ovarian transcriptome in intact, uninduced animals. Increased transcript levels of several markers of oocytes and follicles concomitant with significantly higher residual follicle counts were observed in multiparous ovaries. A second gene-expression pattern overexpressed in aged multiparous ovaries was correlated with circulating chemokines levels, and revealed a functional enrichment in leukocyte chemotaxis and the regulation of innate immunity and inflammation. The results are discussed regarding how such higher residual follicular remnants confer an improved immunosurveillance capacity to the aged multiparous ovary, thereby reducing the risk of neoplasia initiation in the ovary.

\section{Materials and Methods}

\subsection{Animals, Study Scheme, and Sample Collection}

This study with female C57BL/6 mice was approved by the Bioethics Committee, Faculty of Medicine, University of Chile (CBA \# $0536 \mathrm{FMUCH}$ ). The care and monitoring of the two experimental groups, virgin and multiparous, have recently been described in detail [18]. Figure 1A depicts the experimental design for the present report. Briefly, a subset of 12 animals ( $n=6$ per group) around 16-months old was euthanized to collect ovaries for RNA extraction and subsequent gene expression profiling with microarrays (see below). At 20 months old, another subset of 34 mice ( $n=16$ virgin, $n=18$ multiparous) was euthanized to dissect ovaries for follicle count. Sera were obtained from a third subset ( $n=8$ per group) from the blood samples collected twice per month from 17-20 months 
old. Both ovarian tissue and serum samples from four-month-old mice ( $n=6$ per group) were used as a reference.

\subsection{Count of Ovarian Follicles}

The dissected ovary pairs were fixed in $1 \% p$-formaldehyde and embedded in paraffin. The largest longitudinal sections, $5-\mu \mathrm{m}$ thick, were stained with haematoxylin-eosin (HE) and mounted in Entellan ${ }^{\circledR}$ (Merck, Darmstadt, Germany). Primordial, primary, preantral, secondary, and Graafian follicles were identified according to the morphological criteria of Griffin et al. [19], with one single modification, namely: both the incipient and small antral follicles described by these authors are named here as secondary follicles. The follicle counts per sample consisted of the sum of each follicle type in the largest single longitudinal section containing the ovary pair. Multiparous animals had at least two litters (range 2-7, mean 3.5). The mean ages were 21.71 and 20.94 months old for virgin and multiparous mice, respectively.

\subsection{Microarray Profiling of Mouse Ovaries}

One-channel bead-DNA microarrays (MouseRef-8 v2.0, Illumina, Foster City, CA, USA) composed of 25,697 probes (80-mer) covering 17,640 unique coding genes were used. Each probe was represented $25-45$ instances in a single microarray for a total of over 900,000 probes per microarray. A set of 17 microarrays comprised young $(n=6)$, aged virgin $(n=5)$, and aged multiparous $(n=6)$ ovary samples. The total ovarian RNA was isolated with an All-Prep kit (Qiagen, Hilden, Germany, GmbH), treated with Turbo-DNAse (Ambion, Austin, TX, USA), precipitated with sodium acetate plus absolute ethanol, and stored at $-80^{\circ} \mathrm{C}$ until use. The RNA was quantified by UV spectrophotometry (A260/A280 nm) and verified for integrity with an Agilent 2100 Bioanalyzer (Agilent Tech, Palo Alto, CA, USA). All of the RNA samples had RNA integrity (RIN) values $>7.5$. Transcriptional profiling was performed by the service provider Macrogen Inc. (Seoul, Korea). Further experimental details are given in Supplementary File 2.

\subsection{Analysis of Transcriptomic Data}

The scanned images were analyzed with the Illumina Genome Studio v2011.1, gene expression module v1.9.0. The raw data was deposited at the NIH's-National Cancer Institute microarray database (http://nciarray.nci.nih.gov). After quantile normalization, the differentially expressed genes (DEGs) were determined by limma tests with FDR adj $p$-values $<0.05$ and $\log _{2}$ fold-change (FC) $> \pm 1.0$ for the young-aged comparison. The cut-offs for the aged virgin-aged multiparous comparison were FDR adj $p$-values $<0.10$ and $\log _{2}$ FC $> \pm 0.8$. Quality threshold clustering (QTC), heatmaps, and centroid plots were done with $\mathrm{MeV}$ (http://mev.tm4.org/). Gene ontology (GO) enrichment was done with Visual Annotation Display(VLAD) v1.5.1 (http://proto.informatics.jax.org/prototypes/vlad/) and WebGestalt (http://www.webgestalt.org/). Gene Set Enrichment Analysis (GSEA) was done at (http://software.broadinstitute.org/gsea/index.jsp). Protein-protein interaction networks were analyzed with STRING-v11.0 (https://string-db.org/). Mouse immune cell gene expression data were extracted from the Ref-DIC database (http://refdic.rcai.riken.jp/profile.cgi).

\subsection{Determination of Circulating Chemokines}

Mouse cytokines CXCL1, CXCL2, CXCL5, CCL3, and CSF3 were quantified in serum using the multiplex, magnetic bead-based assay MCYTMAG-70K-PX32 panel from Milliplex ${ }^{\circledR}$ (Merck, Kenilworth, NJ, USA), following instructions by the manufacturer, as previously described [18]. Before running the assay, samples were randomized, and their identities were made blind to the operators. Additional experimental details are provided in Supplementary File 2. 
A
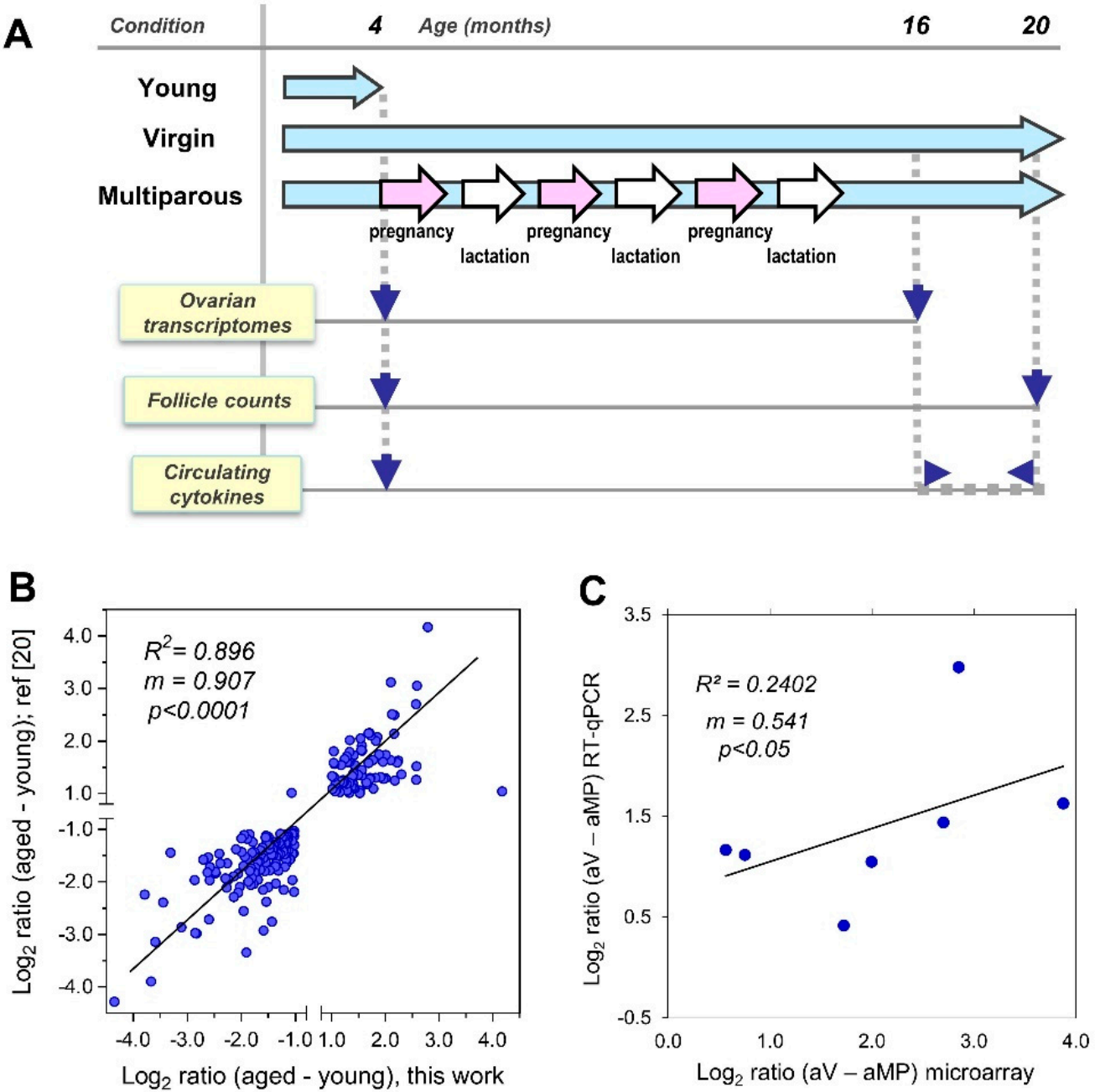

Figure 1. Study flowchart and platform validations: (A) Female C57BL/6 mice were housed from 3 to 20 months in virgin (nulliparous) and multiparous conditions ( $n=70$ per group). A group of young adult, four-month-old virgin mice $(n=20)$ was used as a reference. Transcriptomic profiling was done in young $(n=6), 17$-month-old virgin $(n=5)$ and 17-month-old multiparous mice $(n=6)$. The follicle count was performed in young $(n=3), 20$-month-old virgin $(n=16)$ and 20-month-old multiparous mice $(n=18)$. Serum cytokines were measured at the diestrous stage in adult young, four-month-old mice $(n=6)$ and in randomly chosen, 16-20 month-old female mice of both virgin and multiparous groups ( $n=4$ per group/month). The time scale shown is not proportional. (B) Scatter plot for a 225 genes subset comparing our expression profiling data in young $(n=6)$ versus aged ovaries, irrespective of parity $(n=11)$, with that obtained with the NIA-22k platform ( $n=2$ per group) [20]. Data points between -1.0 and $1.0 \log _{2}$ range were omitted. (C) Scatter plot depicting RT-qPCR and microarray results for Foxo1, Fst, Fshr, Alas2, Snca, Hba-a1, and Hbb-bt transcripts in the $\log _{2}$ scale for both platforms, so as to compare the transcription of aged-virgin versus aged multiparous ovaries; $n=3$ per group in RT-pPCR assays, $n=5$ aged virgin, and $n=6$ aged multiparous in microarray data. The squared correlation, slope, and $p$-values are shown within the plot.

\subsection{Quantitative RT-PCR Assays}

One $\mu \mathrm{g}$ of DNAse-treated RNA was reverse-transcribed with $20 \mathrm{U}$ of M-MLV (Promega, Madison, WI, USA), oligo-dT plus random hexamer primers for $1 \mathrm{~h}$ at $42{ }^{\circ} \mathrm{C}$, and then inactivated for $10 \mathrm{~min}$ at $70^{\circ} \mathrm{C}$. Quantitative PCR was performed by combining an aliquot of the resultant cDNA with $1 \mu \mathrm{M}$ final of each forward and reverse primers and Sensimix Sybr HI-ROX reagent (Bioline, London, UK). Primer pairs were designed with the Primer3-Plus software [21]. Three samples per experimental 
condition and triplicate technical assays per sample were performed in a RotorGene ${ }^{\mathrm{TM}}$ thermocycler (Corbett Life Sciences, Sydney, Australia). Further details in Supplementary File 2.

\subsection{Statistics}

The follicle counts and cytokine levels were plotted as mean \pm standard error of the mean. The data did not follow a normal distribution, and were compared as non-paired data between the aged groups by using Mann-Whitney tests (non-parametric). Significance was set at $p<0.05$. The analysis was performed with the GraphPad Prism 5.0 software.

\section{Results}

\subsection{Study Scheme and Validation of Platforms}

We recently described the reproductive records, circulating gonadotropin levels, systemic inflammatory status, and intraperitoneal tumor spread in estropausal C57BL6 female mice, as well as the differential accumulation of lipofuscin and hemosiderin in the ovaries of these animals according to their divergent parity history [18,22]. In extending these studies, here, we explore how pregnancy impacts the post-reproductive ovary, with a focus on the residual ovarian reserve and the follicular and cell immunity-related transcriptome (Figure 1A). Firstly, to assess the reliability of this Illumina platform, we compared expression ratios of over 200 differentially expressed genes between aged and young ovaries in the $<-1.0$ and $>1.0 \log _{2}$ ratio range with a related previous study [20], in which the NIA Mouse $44 \mathrm{~K}$ v2.1 and v2.2 platforms were used (Agilent, Santa Clara, CA, USA). As shown in Figure $1 \mathrm{~B}$, we observed a significant positive correlation with a slope close to 1.0, meaning that both the magnitude and direction of the changes were equivalent between the platforms. Also, the levels of seven selected transcripts were confirmed using RT-qPCR, for which the cycling conditions and primer pairs sequences are described in Supplementary File 2. The comparison of the transcript levels between the aged virgin/aged multiparous ovaries measured by both the MouseRef- 8 v2.0 platform and the RT-qPCR assays also revealed a significant positive correlation. The observed slope suggests that the transcript levels were in a different range of magnitudes for each platform (Figure 1C).

\subsection{Remnant Follicles in Aged Mouse Ovaries of Divergent Parity History}

The follicles at various stages were identified and counted in the ovaries of the young and the two aged conditions. Based on the mean follicle counts, the ovaries of both aged groups contained significantly lower total follicle counts compared with the young ovaries, as expected, because of the age-dependent ovarian decline (Figure 2A, rightmost chart).

This result is consistent with the increased levels of gonadotropins and estrous cycle lengthening observed by the 16-20 months-old in this animal cohort [18]. Interestingly, follicle depletion was less pronounced in the ovaries of the aged multiparous than in those of the aged virgin mice. The mean counts of the primordial, primordial plus primary, and total follicles were significantly higher in the aged multiparous relative to aged virgin ovaries (Figure 2A). A simple calculation of [aged multiparous/aged virgin] follicles ratios using mean follicle values, resulted in 2.8 and 1.6 for the primordial and total follicles respectively, which suggests a relative enrichment of primordial follicles in aged multiparous with respect to aged virgin ovaries. This finding agreed with a higher co-expression of the genes involved in the maintenance of the primordial follicle pool or preventing their cyclic recruitment in aged multiparous relative to aged virgin ovaries (see Sections 3.4.1 and 4.1). 

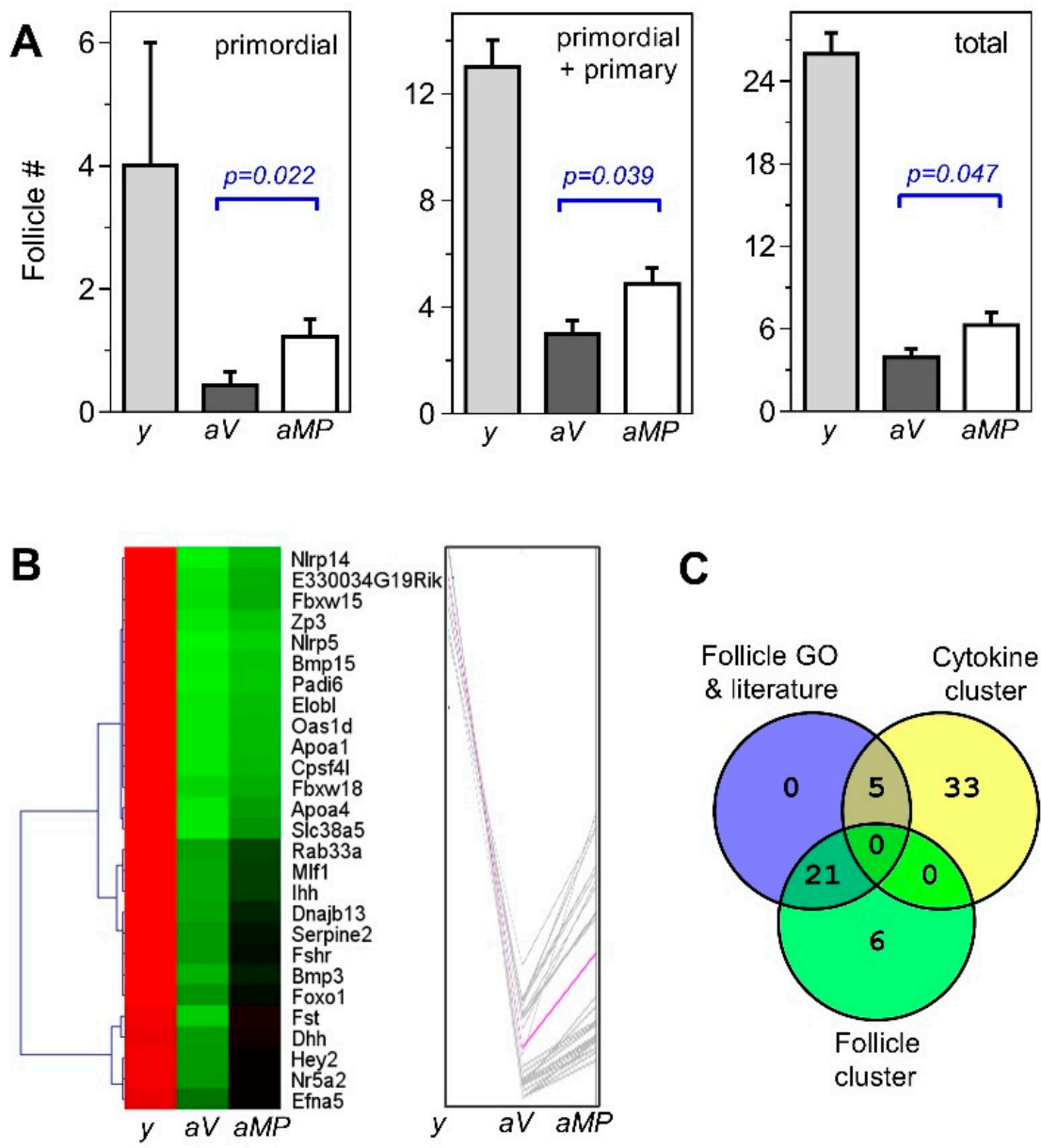

C

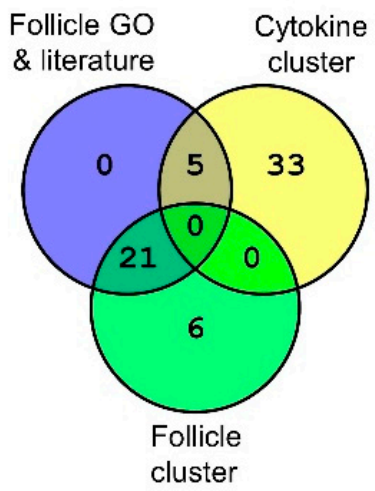

Figure 2. Ovarian follicle counts and cognate ovarian gene expression. (A) Mean ( \pm standard error of the mean (SEM)) primordial, primordial plus primary, and total follicle counts in young (y), aged virgin $(a V)$, and aged multiparous $(a M P)$ ovaries; $p$-values are indicated. (B) Heatmap of the follicular-like signature (27 differentially expressed genes (DEGs); rows) in ovaries of the three experimental groups $(y, a V$, and $a M P)$ showing mean absolute levels of quantile normalized $\log _{2}$ scale values. Quality threshold clustering (QTC) clustering was done with MeV (http://mev.tm4.org/) using the Euclidean distance and 0.42 diameter with prior gene/row adjustment divided by root mean square (RMS). The 27-genes cluster was part of the 65 DEGs of a higher expression in the multiparous ovaries (see text). (C) Venn diagram of the 26 follicle associated genes "Follicle GO and literature" according to gene ontology (GO) (Table 2) and literature analysis (Table 3), the 27 genes showing the follicular-like signature, "Follicle cluster", and the 38 genes of the "Cytokine cluster" (see Section 3.6).

\subsection{The Differential Mouse Ovarian Transcriptome: Age and Parity Comparisons}

To study the effect of age and parity history on the mouse ovarian transcriptome, limma tests were conducted for the following two-group comparisons: First, young ovaries $(n=6)$ versus aged ovaries irrespective of parity status $(n=5+6=11)$ resulted in 905 DEGs $\left(\operatorname{adj} p<0.05\right.$ and $\pm 1.0 \log _{2}$ FC). This comparison allowed us to interpret parity differences below (Section 3.4) over an aged "baseline" gene transcription. This gene list was decomposed in 489 up-regulated and 416 down-regulated genes in aged relative to young ovaries. To our knowledge, transcriptomic studies of post-reproductive versus fertile-age human ovaries have not been reported so far. Just two proteomic studies compared pre- versus post-menopausal ovaries in small ( $n=3-4$ per group) sample sizes (Table 1$)$. Moreover, neither a single-gene nor transcriptomic parity-dependent gene expression study has been previously addressed in the human postmenopausal ovary. 
Table 1. Previous knowledge on gene expression in the human post-menopausal ovary.

\begin{tabular}{|c|c|c|}
\hline Gene (alias) & Context (PMIDs) $^{a}$ & Ovarian Expression (This Work) \\
\hline FST (follistatin) & Residual steroidogenesis; stroma (12519894) & Yes ${ }^{\mathrm{b}} ; \uparrow$ multiparous \\
\hline GREM1 (gremlin-1) & Residual steroidogenesis; stroma (12519894) & Yes; $\uparrow$ multiparous \\
\hline LHCGR (LH receptor) & Detected in OSE, cysts and stroma $(22207559,16253961)$ & No ${ }^{c} ; \uparrow$ aged \\
\hline FSHR (FSH receptor) & Detected in OSE, cysts and stroma (22207559) & Yes; $\uparrow$ multiparous \\
\hline HSD3B (3ß-hydroxysteroid dehydrogenase) & Detected in the cortical stroma (2643063) & $\mathrm{NDE}^{\mathrm{d}}$ \\
\hline$P R$ (progesterone receptor) & Detected in OSE, cysts and stroma $(19056530,20552551)$. & NDE \\
\hline ESR1 (estrogen receptor alpha) & Detected in OSE, cysts and stroma $(18165170,20552551)$. & NDE \\
\hline CYP19A1 (aromatase) & Detected in OSE, cysts, stroma and vascular endothelium (24855493) & NDE \\
\hline HSD17B1 (17 $\beta$-hydroxysteroid dehydrogenase) & Detected in OSE, cysts, stroma and vascular endothelium (24855493) & Yes, $\uparrow$ multiparous \\
\hline$A R$ (androgen receptor) & Detected in the OSE, cysts and stroma (20552551) & NDE \\
\hline APCS (serum amyloid P component) & Differential pre-/post-menopausal proteome (25037597) & No; $\uparrow$ young $(*)$ \\
\hline HSPB1 (Hsp27) & Differential pre-/post-menopausal proteome (25037597) & NDE \\
\hline GLO1 (glyoxalase-I) & Differential pre-/post-menopausal proteome (25037597) & NDE \\
\hline UCHL1 (ubiquitin C-terminal hydrolase L1) & Differential pre-/post-menopausal proteome (25037597) & No; $\uparrow$ young \\
\hline
\end{tabular}

a PMID stands for PubMed unique identifier. " "Yes" indicates a gene appearing in the 177 DEGs according to parity history (see Section 3.2). Arrow indicates predominant multiparous or nulliparous expression. ${ }^{c}$ " $\mathrm{No}^{\prime}$ " indicates that expression was not parity-dependent, but only part of the 904 DEGs according to age (see Section 3.2). Arrow indicates predominant young versus aged expression. ${ }^{d}$ NDE: Non differentially expressed gene in either the aged-young or the aged virgin-aged multiparous comparisons. * Differential expression with $p<0.05$ but under the fold change threshold. OSE-ovarian surface epithelium.

The gene ontology (GO) analysis indicated that, regardless of parity history, aged ovaries expressed a minimal repertoire of mitotic, cell cycle, and DNA repair genes, but a high content of genes implicated in inflammatory/immune responses, cell adhesion, TNF production, peptidase activity, and wound healing (Figure 3A). These functions agreed to a large extent with those described by Sharov et al. [20], and essentially reflect a typical senescent status with a low proliferative activity, increased tissue remodeling, and innate immune cross-talk, leading to chronic low-grade tissue inflammation known as the senescence-associated secretory phenotype (SASP) [23]. High expression levels of over two-dozen distinct cytokines, interleukins, their respective receptors, and interferon-related genes, in addition to typical macrophage, neutrophil, lymphocyte, and mast cell markers were detected in aged mouse ovaries (not shown). These included F4/80 (Adgre1), CD68, CD86, class II H2 complex (H2-Aa, Ab1, $D M a, D M b 1$, and Eb1), Ly6 complex ( $a, d$, and e loci), CD3 complex (Cd3e, $d$, and $g), C D 44$, and proteases (Cpa3 and Cma1). Furthermore, all of the GO terms describing the activation of the leukocyte, lymphocyte, macrophage, neutrophil, and mast cells were significantly enriched in the aged relative to young ovaries. The same trend was observed for the terms of "phagocytosis", "lysosome", "cell surface receptors", and "cytokine-mediated signaling", which are closely related to the SASP. Consistent with this local ovarian inflammation associated with the reproductive decline, we previously showed an age-dependent increase of systemic levels of several cytokines in this mouse cohort, including TNF-alpha, IL1-beta, CCL2, IL-10, IL-5, and IL-4, among others [18].

The second comparison was done between aged ovaries only, and was based on their parity history, that is, virgin $(n=5)$ versus multiparous $(n=6)$. This resulted in 177 DEGs (adj $p<0.10$; $\pm 0.8 \log _{2}$ FC), which were decomposed in 65 up-regulated and 112 down-regulated genes in aged multiparous respective to aged virgin ovaries.

\subsection{Gene Ontology Profile of the Aged Multiparous Mouse Ovary}

Given the known effect of past pregnancy on OC risk in menopause [11], the analysis in this report was focused on the 65 DEGs of a higher expression in aged multiparous with respect to aged virgin ovaries. As shown in Figure 3B and summarized in Table 2, a significant enrichment in GO terms related to four major interrelated themes was observed, namely: (i) follicle and oocyte homeostasis, (ii) cell immunity and inflammation, (iii) transcriptional regulation, and (iv) cell death. The GSEA analysis pointed to a modulation of receptor activities, cell-cell signaling, and cell-extracellular matrix relationships (Figure 3C). The genes not appearing in Table 2 were Serpine2, Cxxc4, Chrna4, Sorcs3, and Phex, all under cell-cell signaling; except for Serpine2, this subset demonstrated a cytokine-like pattern (see Section 3.6), thus reinforcing the relevance of cell immunity and inflammation in the present analysis. 


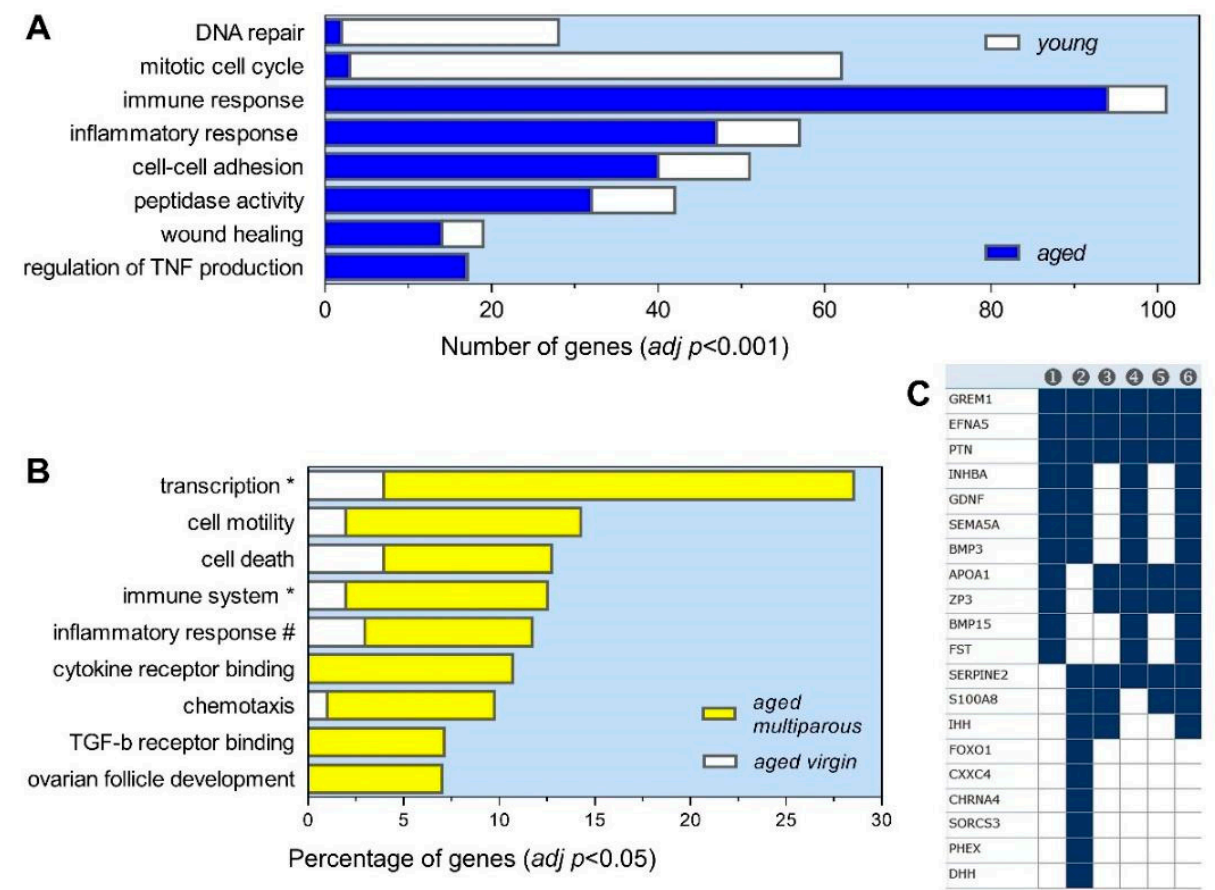

Figure 3. Gene ontology (GO) profile of differentially expressed genes in aged ovaries. Analysis of DEGs between (A) aged versus young, and (B) aged virgin versus aged multiparous ovaries after limma tests, as described in Methods. The aged/young test resulted in a similar number of up- and down-regulated genes. As the aged virgin/aged multiparous comparison resulted in unbalanced up- and down-regulated gene numbers (65 versus 112), the GO enrichment was converted into percentages. The VLAD tool was run with official $M$ musculus gene symbols (adj $p<0.05$; gene function annotation from Mammalian Genome Informatics (MGI)) with default parameters. Abbreviated GO terms: $\left(^{*}\right.$ ) "positive regulation of"; (\#) "regulation of". (C) GSEA analysis of the genes upregulated in multiparous ovary using the C5 (GO) collection. Column headings are (1) receptor regulator activity (11 genes), (2) cell-cell signaling (16 genes), (3) extracellular matrix (10 genes), (4) molecular function regulator (16 genes), (5) collagen containing extracellular matrix (9 genes), and (6) signaling receptor binding (15 genes). All the terms met an FDR $q$-value $<4.1 \times 10^{-5}$.

Table 2. Enriched GO terms in genes of higher expression in aged multiparous ovaries ${ }^{\text {a }}$.

\begin{tabular}{|c|c|c|}
\hline Functional Theme & GO Terms Associated & Genes \\
\hline Follicle and oocyte homeostasis & $\begin{array}{l}\text { Ovarian follicle development } \\
\text { Germ cell development } \\
\text { TGF-beta receptor binding } \\
\text { BMP signaling } \\
\text { Steroid metabolic process }\end{array}$ & $\begin{array}{c}\text { Bmp15, Fshr, Inhba, Oas1d, Dhh, Ihh, } \\
\text { Zp3, Gdnf, Bmp3, Fst, Grem1, } \\
\text { Hsd17b1, Apoa1, Apoa4, and Nr5a2 }\end{array}$ \\
\hline Cell immunity and inflammation & $\begin{array}{c}\text { Regulation of inflammatory response } \\
\text { Positive regulation of immune system } \\
\text { process } \\
\text { Chemotaxis } \\
\text { Cell migration }\end{array}$ & $\begin{array}{c}\text { Apoa1, S100a8, Zp3, Fpr2, Ihh, } \\
\text { Inhba, Masp1, Rftn2, Sema5a, Fgf13, } \\
\text { Gdnf, Grem1, and Efna5 }\end{array}$ \\
\hline Transcription & $\begin{array}{c}\text { Positive regulation of transcription, } \\
\text { DNA-templated } \\
\text { Transcription factor activity, } \\
\text { sequence-specific DNA binding }\end{array}$ & $\begin{array}{c}\text { Bmp15, Bmp3, Cdk5rap2, Dbp, } \\
\text { Foxo1, Gdnf, Grem1, Hey2, Hoxd10, } \\
\text { Hoxd9, Ihh, Inhba, Nr5a2, and Zp3 }\end{array}$ \\
\hline Cell death & $\begin{array}{c}\text { Cell death } \\
\text { Positive regulation of apoptotic process }\end{array}$ & $\begin{array}{c}\text { Nlrp5, S100a8, Serpina3g, Foxo1, } \\
\text { Inhba, and Ptn }\end{array}$ \\
\hline
\end{tabular}

${ }^{a}$ GO analysis was done with VLAD. Enrichment was more than two-fold with adj $p<0.05$. The analysis covered 31 of the 65 DEGs of a higher level in aged multiparous versus aged virgin ovaries. BMP-bone morphogenetic protein. 


\subsubsection{Follicle and Oocyte Homeostasis}

Bmp15, Fshr, Inhba, and Oas1d are annotated under "ovarian follicle development", while Dhh, Ihh, and Zp3 are annotated under "germ cell development". Bmp3, Bmp15, Gdnf, and Inhba also display a "TGF-beta receptor binding activity", whereas Bmp3, Bmp15, Grem1, and Inhba are indexed under the "regulation of pathway-restricted SMAD protein phosphorylation". TGF- $\beta$-related genes Bmp15, Bmp3, Fst, and Grem1 are also annotated in GO under the cognate pathway "bone morphogenetic protein (BMP) signaling", while Fst and Grem1 are classified as TGF- $\beta$ antagonists. The GSEA analysis analogous to that of Figure 3C identified six genes in the C2-GCP overlap that were down-regulated in female Smad1/Smad5 conditional mutants that developed metastatic granulosa cell tumors [24]. SMAD proteins are the major signal transducers downstream of TGF-beta. A different nine-gene overlap was found to be upregulated in the uterus of Bmp2 knock-out mice [25], and this might be interpreted as equivalent to the inhibition of BMP signaling by Fst and Grem 1 antagonists. An additional follicle-related pathway enriched in the aged multiparous ovary was the "steroid metabolic process" comprising the genes Hsd17b1, Apoa1, Apoa4, and Nr5a2. Including the Hedgehog signaling members Ihh and Dhh, known to modulate steroid biosynthesis in various organs, including the ovaries [26], there were six steroidogenic genes overexpressed in the aged multiparous relative to the aged virgin ovary.

As shown in Table 2, 15 of the 65 genes with a higher expression in the aged multiparous ovaries were indexed in oocyte/follicle related terms, according to the GO database. We additionally performed a manual literature search for oocyte/follicle associated genes, and found 11 further genes with experimental support to be involved in this function (Table 3). Therefore, a total of 26 out of the 65 (i.e., 41.5\%) genes overexpressed in the aged multiparous with respect to aged virgin ovaries had evidence of roles in oocyte/follicle homeostasis.

Table 3. Follicle and oocyte-related genes not annotated in $\mathrm{GO}^{\mathrm{a}}$.

\begin{tabular}{ccccc}
\hline Gene & Fold Change $\mathbf{b}^{\mathbf{b}}$ & Role in Ovarian Biology & PMID \\
\hline Nlrp14 & 6.6 & Innate immunity of oocytes & 28423339 \\
Slc38a5 & 5.2 & Paralog Slc38a3 is expressed in adult mouse granulosa cells & 23083410 \\
Padi6 & 5.1 & Part of cytoplasmic lattice and cytoskeletal sheets in oocytes & 17587491,27929740 \\
Nlrp5 & 4.6 & ER, calcium and mitochondrial homeostasis of oocytes & 24374158,22357545 \\
Cpsf4l & 2.9 & Expressed in adult mouse granulosa cells & 23083410 \\
E330034G19Rik & 2.8 & Oocyte specific in mouse; meiotic maturation & 17567914 \\
Hey2 & 2.7 & Notch target involved in oocyte-follicle growth balance & 24552588 \\
Fbxw15 & 2.4 & Oocyte specific. Follicle assembly and early follicle growth & 18094359 \\
Serpine2 & 2.2 & Cumulus cell marker of oocyte maturation & 23082142 \\
Efna5 & 2.0 & Regulates proliferation and apoptosis of granulosa cells & 29619874 \\
Kcne2 & 1.9 & Expressed in adult mouse granulosa cells & 23083410 \\
\hline
\end{tabular}

${ }^{\text {a }}$ Genes in this table are part of the 27 genes with a follicular-like expression pattern (highest level in young, lowest in aged virgin, and intermediate in aged multiparous ovaries), as shown in Figure $2 \mathrm{C} .{ }^{\mathrm{b}}$ The fold change here corresponds to the [aged-multiparous/aged virgin] expression ratios in the direct linear scale.

\subsubsection{Cell Immunity and Inflammation}

Included here were the GO terms "regulation of inflammatory response" (Apoa1, Nlrp14, Nlrp5, S100a8, and Zp3), "positive regulation of immune system process" (Fpr2, Ihh, Inhba, Masp1, Rftn2, and Zp3), "chemotaxis" (Apoa1, Efna5, Fpr2, S100a8, and Sema5a), and "cell migration" (Apoa1, Fgf13, Fpr2, Gdnf, Grem1, S100a8, and Sema5a). Among these 12 genes, Fpr2 and S100a8 overlap in three of the four GO terms mentioned. Fpr 2 codes for a member of the G-protein coupled formyl peptide receptor family, whereas $\mathrm{S100a8}$ codes for calgranulin-A, which is $\mathrm{Ca} / \mathrm{Zn}$ binding protein that heterodimerizes with the calgranulin-B isoform. Both proteins confer a chemoattractant capacity to neutrophils and monocytes (see discussion). 


\subsubsection{Transcriptional Regulation}

This function comprised the GO term "positive regulation of transcription, DNA-templated" (Bmp15, Bmp3, Cdk5rap2, Dbp, Foxo1, Gdnf, Grem1, Hey2, Hoxd10, Hoxd9, Ihh, Inhba, Nr5a2, and Zp3). Six of these 14 genes (Dbp, Foxo1, Hey2, Hoxd10, Hoxd9, and Nr5a2) are annotated under the term "transcription factor activity, sequence-specific DNA binding".

\subsubsection{Cell Death}

The relevant GO terms containing the genes of the three themes above described were "cell death" (Figure 2B) and the "positive regulation of apoptotic process" (not shown). These terms comprised the gene Ptn plus the other five genes already mentioned (Foxo1, Inhba, Nlrp5, S100a8, and Serpina3g).

\subsection{Correlation of Follicle Counts with the Ovarian Transcriptome}

For this analysis, the transcriptome results were analyzed across the three experimental groups, (i.e., young, aged virgin and aged multiparous ovaries). The quality threshold clustering (QTC) algorithm was applied to the normalized expression levels of the 65 DEGs between the aged ovaries, and included the expression levels observed in young ovaries. This resulted in the following three clusters: 27 (Figure 2B), 32, and 6 genes (Figure 4B,D). Notably, the centroid pink colored line of the 27-genes cluster (Figure 2B, right) resembled the follicle count pattern depicted in Figure 2A (i.e., highest in young, lowest in aged virgin, and intermediate level in aged multiparous ovaries), and thereby it may be considered a "follicular-like" signature. Importantly, 11 from the 15 genes annotated in the GO terms related to oocyte-follicle homeostasis (Table 2), and 10 of the 11 genes with manually collected evidence of roles in oocyte-follicle homeostasis (Table 3) showed this follicular signature (Figure 2B). These 21 genes are shown in the intersection between "Follicle GO and literature" and "Follicle cluster" in the Venn diagram of Figure 2C. Interestingly, the intersection between "Follicle GO and literature" and "Cytokine cluster" captured five genes with a cytokine-like pattern, but functional evidence of follicle-oocyte involvement (Figure $4 \mathrm{~B}$, blue dot labels). These were Inhba, Gdnf, Grem1, Hsd17b1, and Kcne2. Finally, the genes Apoa1, Gdnf, Grem1, Ihh, Inhba, and Zp3, were common between the follicle/oocyte and immune/inflammatory themes based on GO. Similarly, Inhba, Gdnf, and Grem1, besides linking the follicle/oocyte and immune/inflammatory themes, exhibit a transcriptional modulation activity and take part in the cytokine-like gene regulatory network (Figure 5B).

\subsection{Parity-Dependent Serum Cytokine Levels and Correlation with the Ovarian Transcriptome}

Previously, we reported circulating levels of seven cytokines that increased with reproductive aging irrespective of parity records, and then decreased in response to tumor induction exclusively in multiparous compared with virgin mice [18]. Here, we show serum levels of other cytokines in intact (non-tumor induced) mice that, except CXCL1, remained unchanged between young and aged virgin mice, while increased significantly in aged multiparous animals. Figure $4 \mathrm{~A}, \mathrm{C}$ shows circulating levels of cytokines CXCL1 (GRO-alpha/KC), CXCL2 (MIP-2/GRO-beta), CXCL5 (LIX/ENA-78), CCL3 (MIP1-alpha), and CSF3 (G-CSF) in young, aged virgin, and aged multiparous mice. The aged multiparous mice showed the highest CCL3 and CSF3 levels. The [aged multiparous/aged virgin] mean ratio levels of these five cytokines ranged from 4.2-fold for CSF3 to 1.6-fold for CXCL2.

Interestingly, the cytokine serum levels were mirrored by the expression patterns of two clusters containing 32 (Figure 4B) and 6 (Figure 4D) significantly up-regulated genes in multiparous compared with virgin ovaries. This cytokine-like profile substantially differed from the above mentioned follicular-like pattern (27-genes), in that their mean gene expression levels in young ovaries were not drastically higher than those of the aged ovaries. Notably, the leukocyte chemoattractant genes Fpr2 and S100a8 were among the six-genes cluster showing the highest expression levels in the three conditions (Figure 4D). 

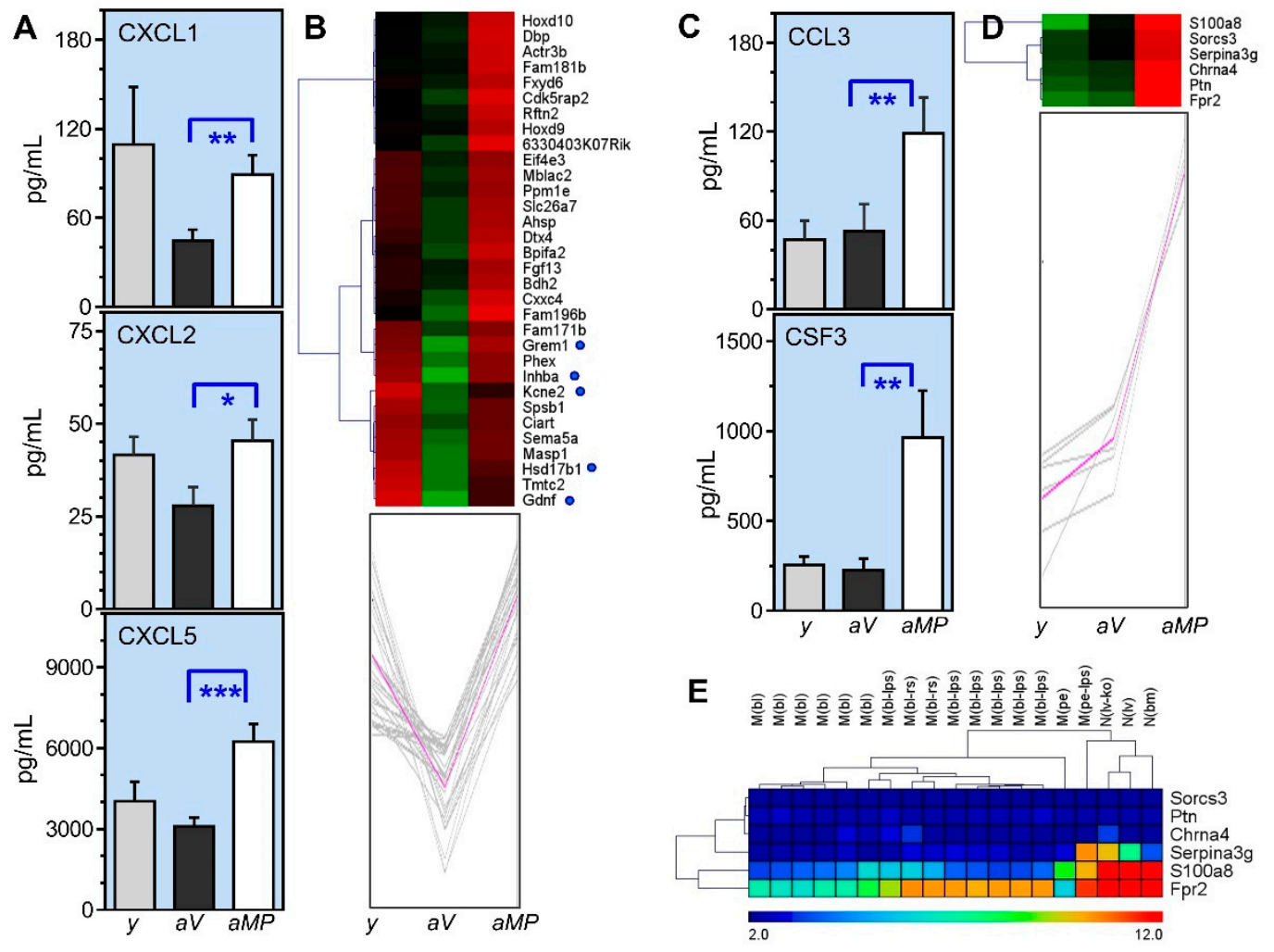

Figure 4. Parity-dependent circulating cytokines levels and related gene expression in aged ovaries: $(\mathbf{A}, \mathbf{C})$ Mean $( \pm$ SEM) serum levels of the indicated cytokines in female young $(y)$, aged virgin $(a V)$, and aged multiparous ( $a M P)$ mice are shown with their respective 32-genes (B), and the six-genes (D) expression heatmaps and centroid clusters at the bottom obtained with same settings as that of Figure 2 . Significant differences among the cytokine levels were determined after two-tailed Mann-Whitney tests, $\left.\left.{ }^{*}\right) p<0.05,{ }^{* *}\right) p<0.01$, and $\left.{ }^{* * *}\right) p<0.001$. Blue dots in the heatmap of $(\mathbf{B})$ indicate genes with a cytokine-like pattern, but evidence of follicle function. Note that the sum of 27-genes (Figure 2B) and the 32 and 6 (38) genes in (B,D) complete the 65 DEGs of a higher expression in multiparous ovaries (see Section 3.3). The heatmap in (E) show the expression levels of the six-gene clusters in peritoneal and intact LPS-treated J774.1 macrophages (M label) and neutrophils (N label). Multiple samples correspond to different LPS doses and incubation times, as described in the Ref-DIC database (http://refdic.rcai.riken.jp/profile.cgi).

The presence of immune cells in the ovary, with macrophages as the more abundant, is inherent to various physiological processes during fertile life, including follicle maturation, ovulation, luteogenesis/luteolysis, atresia, and vascular integrity [27-29]. As follicle depletion and ovarian aging progress, this immune cell content and their activities would become modulated by the SASP effect. Thus, the genes composing this cytokine-like pattern were mined in the Reference Database of Immune Cells (Ref-DIC) [30], with an emphasis on the neutrophil and macrophage gene expressions.

As shown in Figure 4E, Fpr2, S100a8, and Serpina3g are expressed in detectable levels in these two cell types. Both peritoneal and J774.1 (blood) macrophages show an increased Fpr2 expression in response to a pro-inflammatory stimulus (LPS) at various times and doses, while the Fpr2 expression by neutrophils is constitutively high. The Serpina3g expression was enhanced only in LPS-stimulated peritoneal macrophages and in the liver neutrophils from Tcra knockout mice. On the other hand, S100a 8 was weakly induced by LPS in macrophages, but highly expressed by the three neutrophil types shown without any stimulus. Regarding the cluster of 32 genes, Ref-DIC demonstrated high (Eif4e3, $D t x 4$ ) and moderate (Cdk5rap2, Dbp, Actr3) expression levels in the J7774.1 macrophages. Interestingly, Ihnba showed a high expression exclusively in peritoneal macrophages (data not shown). A recent report found that LPS treatment improved the innate immunity in a xenograft model of SKOV3 cells in 
CD-1 mice, resulting in extended survival and increased CXCL1 levels [31], one of the chemokines that was also detected here at higher levels in multiparous mice (Figure $4 \mathrm{~A}$ ).

\subsection{Network Analysis of Gene Clusters of Higher Expression in the Multiparous Ovary}

The genes comprising the follicle and cytokine clusters display some degree of overlap in enriched GO terms shown in Figure 2B and Table 2. Aimed to visually illustrate such an overlap and to uncover novel gene relationships, protein-protein interactions (PPI) networks were constructed with STRING v11.0 on both the 27 genes cluster referred to as the follicular-like signature, and the 38 (32 and 6) genes cluster corresponding to the cytokine-like signature defined in Section 3.4. The network of Figure 5A depicts Fst, Fshr, Zp3, Bmp15, Oas1d, and Padi6 as major interconnected hubs among the descriptors at the bottom.

The networks shown in Figure 5 were obtained by adding the official gene symbols of the five cytokines measured in serum to each of the 27 or the 38 genes listed separately prior to running the STRING tool. Notably, only the network formed with the cytokine-like cluster (38 genes) showed significant known and predicted links between the proteins coded by those genes and the five cytokines. S100a8 is indexed in three of the four GO terms at the bottom, and showed links with Fpr2 and the three CXC cytokines only. In turn, all of the cytokines, except CSF3, were connected to Fpr2 (Figure 5B). Precisely, these two genes overlap the majority of GO terms related to the immunity/chemotaxis component described in Section 3.2.

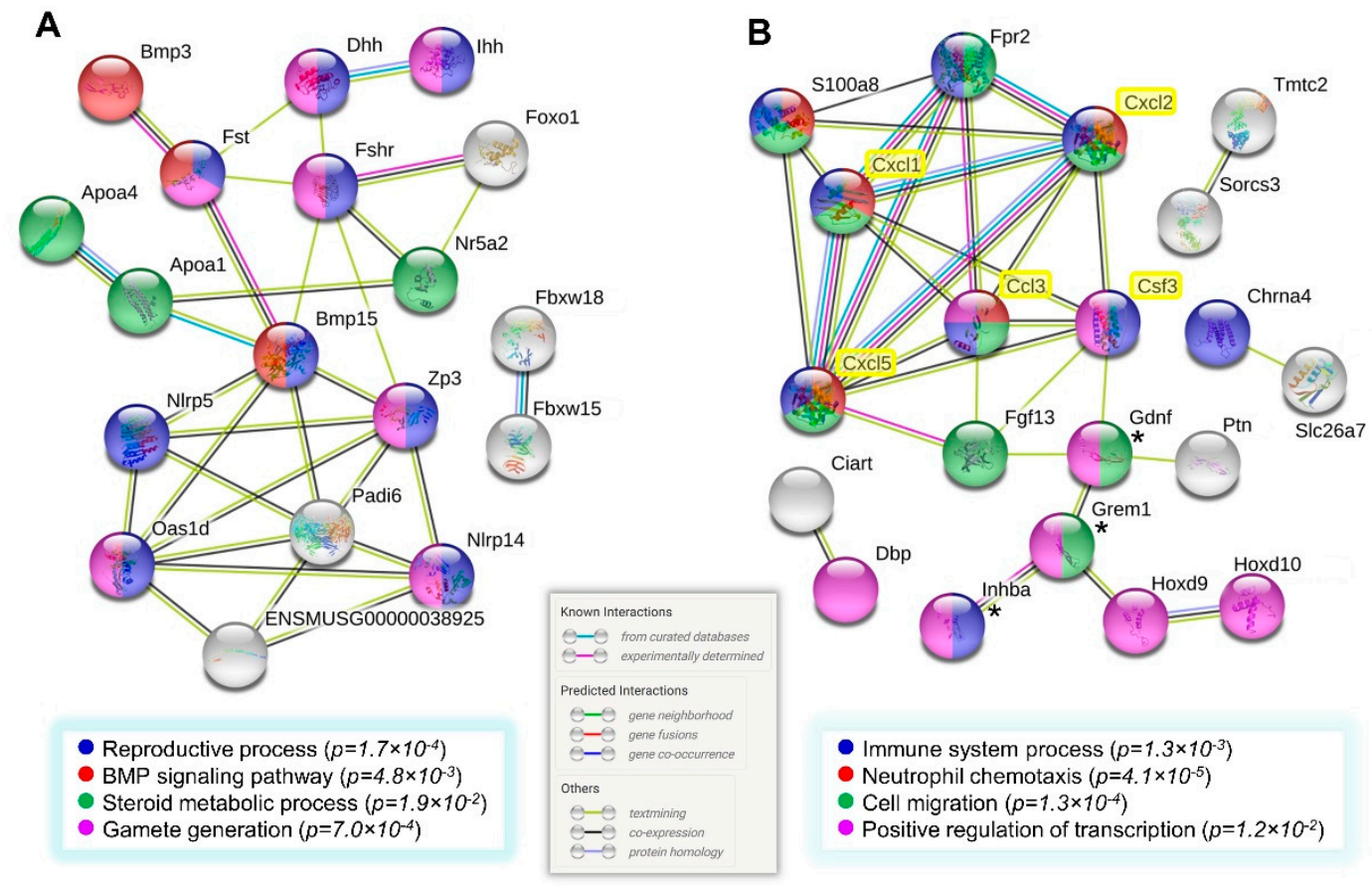

Figure 5. Protein-protein interaction network of genes associated with follicles and innate immunity in aged multiparous ovaries: The follicular-like (A) and the cytokine-like (B) gene clusters were analyzed with STRING v11 for known and predicted relationships existing as protein-protein interaction networks. The corresponding official Mus musculus gene symbols for the cytokines measured in serum were added to both the follicular (27) and the cytokine (32 and 6) clusters separately, to run each analysis. Serum cytokines are highlighted in yellow boxes in (B). The confidence score was set to 0.350 , and the unconnected nodes were excluded from the network. Boxes at the bottom of each network indicate color codes for GO terms enriched in the respective protein networks (adj $p<0.05$ ). ( ${ }^{*}$ ) indicate genes that belong to the cytokine cluster, but show primary evidence of follicle function (see Tables 2 and 3 ). Legend to color-coded interaction lines were adapted from the STRINGv11 output. 


\section{Discussion}

The current knowledge on the gene expression by the aged mammalian ovary is scarce and limited to a debated steroidogenic capacity (Table 1). Epidemiology indicates that parity protects against OC, though the precise mechanism has not been elucidated. Smith and Xu speculated that the "depletion of germ cells and the loss of ovarian follicular function that follows might underlie the link between reproductive factors and ovarian cancer risk" [4]. The postulated protective role of the ovarian reserve against OC is supported by decreased OSE hyperplasia in the presence of a minimal number of follicles in ovaries of the white spotting variant ( $\mathrm{Wv}$ ) mice, a model of ovarian aging and menopause [8]. Thus, we addressed the relationship between parity and follicle depletion in the intact C57BL/6 mouse at estropause (menopause-like) age. Some of the mouse genes detected in the present study might be candidates to validate human postmenopausal ovaries according to parity history and their genetic variants investigated concerning OC risk and associated comorbidities in postmenopausal women.

\subsection{Evidence of Remnant Follicles in the Aged Multiparous Ovary}

Our results suggest that the aged multiparous mouse ovaries contain a higher follicle number and express higher transcript levels of several well-characterized follicle/oocyte related genes compared with the aged virgin ovary. Here, it follows that germ cell depletion is less, owing to pregnancy during prior fertile life. This finding agrees with results by Moini et al. who observed a higher ovarian reserve in parous women of reproductive age (mean 28 years old, range 20-35) measured as antral follicle counts and serum anti-müllerian hormone (AMH) [14]. Then, our data allow to reasonably speculate that this parity-dependent differential ovarian reserve might persist until an advanced age, thereby providing a protective action. In this regard, follicle depletion in women is not absolute at menopause. Approximately 1000 non-growing follicles remain in the human ovary at 51 years old, the mean menopause age [13], whereas the total non-growing follicle exhaustion in women is predicted to occur by 74 years old [32].

Among the follicle-/oocyte-related genes expressed by aged multiparous ovaries, seven were members of the TGF- $\beta$ superfamily, which comprises over 30 conserved protein ligands classified in the following three major subfamilies: TGF- $\beta$ s, activin/inhibins, and BMPs. These ligands are involved in processes such as embryonic development, tissue regeneration, wound healing, immunity, and reproduction. Ovarian TGF- $\beta$ factors participate in somatic and germ cell growth and differentiation, ovulation, and fertilization, and play key roles in primordial follicle formation, assembly, and activation [33]. Inhba codes for the $\beta-A$ subunit of inhibin-A, activin-A, and activin-AB dimers expressed by granulosa cells. Circulating inhibins repress, while activins stimulate pituitary FSH synthesis and release. Female reproductive aging is characterized by increased levels of circulating activin and FSH [34], the latter confirmed in our previous report [18]. Thus, a higher Inhba expression in the aged multiparous ovary suggests elevated levels of the activin-A homodimer. Intraovarian activins promote the autocrine expression of Fshr and Cyp19a1 (aromatase) in pre-antral follicles, while depressing steroidogenesis in advanced-stage follicles and lutein-granulosa cells [34]. Consistently, we detected a higher Fshr expression in aged multiparous with respect to aged virgin ovaries. The coexpression of Cyp19a1 showed the same trend, although not reaching statistical significance. In agreement with our findings, the FSH receptor (FSHR) and aromatase have been localized in the human postmenopausal ovary (Table 1) [35,36].

Other TGF- $\beta$ related genes highly expressed by the multiparous ovary were the ligand antagonists Fst (follistatin) and Grem1 (Gremlin-1) [33]. The proteins coded by these genes were detected in the stromal cells of human postmenopausal ovaries, and are proposed to neutralize the activities of endogenous follicular growth factors [37]. Although the parity status of the ovary samples analyzed by Jabara et al. was not specified [37], it could be assumed that parous postmenopausal ovaries were used. Follistatin is a high-affinity inhibitor of activin that blocks pituitary FSH release. However, as circulating follistatin levels decrease at menopause - in contrast to activins and FSH_the inhibition of systemic activin would not operate at this life stage [38]. Ovarian Fst is expressed as three isoforms that 
regulate the balance between germ-cell nest breakdown and the subsequent assembly of primordial follicles. Mouse Fst overexpression blocks follicle maturation before the antral stage, possibly by inhibiting granulosa cell proliferation [39], a role relevant in the aged multiparous ovary containing residual follicles as our data suggest.

Finally, the oocyte-specific growth factor Bmp15 was another TGF- $\beta /$ BMP transcript showing a parity-dependent differential expression. This BMP is detectable at the primordial stage and regulates the ovulatory rate by preventing the premature activation of primordial follicles [40]. In addition, FSH, which is increased during menopause (and estropause) and signals via Fshr, also restricts activation of primordial follicles as observed in fertility studies [41,42] thus preventing depletion of the resting ovarian follicle pool. Consistent with the above-described preventive roles, Bmp15, Fshr, and Fst are interconnected in the protein network (Figure 5A). The function of TGF- $\beta / B M P$ antagonists BMP15 and activin-A in sustaining Fshr expression, suggest the existence of a higher dormant follicle reserve in the aged multiparous compared with the aged virgin ovary. Follicle count results (Figure 2B) support this idea. Interestingly, the second TGF-beta antagonist detected in this study, Grem1, displayed a cytokine-like pattern (Figure 5B).

\subsection{Former Parity Might Sustain Residual Steroidogenesis in the Aged Ovaries}

The research on post-reproductive ovaries has mostly dealt with its controversial androgenic capacity (Table 1), which would rely on the accumulation of secondary interstitial cells derived from theca cells of atretic follicles [43]. Here, we provide evidence that this ability might be based on a former parity history. As shown in Table 2, six steroidogenic genes were highly expressed in the aged multiparous ovary. Hsd17b1 codes for the type-1, 17-beta hydroxysteroid dehydrogenase, which catalyzes the NADPH-dependent reduction of estrone and androstenedione to estradiol and testosterone, respectively. Given that estrone is produced by aromatase, our data suggest a synthesis of testosterone only, if the HSD17B1 enzyme levels resemble the transcript levels in the multiparous mouse ovary. This conclusion is supported by the presence of testosterone; its precursor androstenedione [44,45]; and the HSD17B1 protein in the OSE, cysts, stroma, and vascular endothelium of human post-menopausal ovaries [36]. Interestingly, given that follicle viability is improved by androgens such as dehydroepiandrosterone (DHEA) in an ovarian aged rat model [46], our data suggest that the steroidogenic capacity of aged ovaries detected in the present and other studies contributes to preserve follicle remnants. Like follicle/oocyte transcripts, steroid synthesis, including androgen production by the human postmenopausal ovary, has not been linked to parity history yet. None of the age-related ovarian gene expression reports compiled in Table 1 specify parity records. Then, it seems plausible to think that the residual steroidogenic capacity detected in the aged human postmenopausal ovary in such studies might be derived from follicle remnants persisting in parous ovaries because of pregnancy during former fertile age.

\subsection{Transcriptional Control in the Aged Multiparous Ovary}

Six genes up-regulated in aged multiparous ovaries display an activity of transcription factor. In general, age-dependent up-regulation involves stress-responsive transcription factors. The forkhead box (FOXO) family of transcription factors is implicated in longevity and aging-related processes, including cell cycle arrest, oxidative stress, DNA repair, apoptosis, and autophagy [47]. Foxo1 is a master regulator of FSH-target genes in granulosa cells [48]. It is highly expressed in growing follicles, repressed during luteinization, and induced in atretic and developing cystic follicles of middle-age acyclic rats at persistent estrous [49]. During fertile age, the apoptotic and autophagic actions of Foxo1 on granulosa cells are associated with oxidative stress and can be inhibited by FSH in mice [50,51]. In the presence of activins, FSH induces AKT-mediated Foxo1 phosphorylation, thereby releasing the nuclear transcriptional repression of steroid and follicle-related genes such as Fshr and Nr5a2, among others [52]. In turn, $N r 5 a 2$ is a zinc finger transcription factor (orphan nuclear hormone receptor) essential for luteinization [53]. Thus, our findings on Foxo1, Fshr, and Nr5a2 co-expression under 
persistent FSH stimulation in the presence of activin-A (Inhba), suggest phosphorylated Foxo1 in the aged multiparous ovary. This conclusion is reflected in the follicular-like protein network shown in Figure 5A. If this transcriptional pattern is preserved at a protein level, we hypothesize that a direct interaction of Foxo1 with membrane-localized Fshr to form an atypical signaling complex would preclude the nuclear translocation of Foxo1 in aged multiparous ovarian cells, as observed in HEK 293 cells [54].

Also, the Notch target Hey2 codes for a myc-type basic helix-loop-helix transcription factor highly expressed in the adult mouse ovary (https://www.ncbi.nlm.nih.gov/gene/15214\#gene-expression). Hey 2 connects TGF- $\beta$ and Notch pathways during proliferation of pre-antral granulosa cells [55] and modulates the homeostasis of the somatic-germ cell syncytia during follicular development [56]. Importantly, Notch signaling has been recently associated with innate immunity and the onset of inflammatory, age-related diseases [57].

\subsection{Parity History Improves the Ovarian and Systemic Immune-Chemotactic Activity of Aged Mice}

Ovarian processes, including ovulation, luteinization, and atresia, depend on a delicate pro-/anti-inflammatory balance relying on leukocyte activities [27-29,58]. Macrophages are the most abundant ovarian leukocytes, and their function in the ovary and other sections of the female reproductive system during fertile age is modulated by estrogens to induce the alternative, M2 anti-inflammatory, tissue repair differentiation profile [29]. The available information about ovarian immunity and inflammation during the postmenopausal phase and parity history is scarce.

Higher circulating levels of CXCL1, CXCL2, CXCL5, CSF3, and CCL3 were detected in aged multiparous mice. This cytokine set participates in the innate immune response to endogenous tissue damage and infection mainly in initial phases [59]. A role in leukocyte extravasation to inflammatory lesions is suggested by the co-localization of CXCL1, CXCL2, and CXCL5 in granules of a subset of vessels in healthy mouse skin and platelets [60]. Fertile-age human granulosa-lutein cells express high levels of CXCL2 and other cytokines after prostaglandin F2-alpha treatment or the removal of luteotropic stimulants, suggesting a role in luteolysis [61]. The neutrophil-recruiting abilities of these chemokines depend on activation and binding to their CXCR1 and CXCR2 receptors [59]. Consistently, in our results, the $C x c r 1$ gene was upregulated almost six-fold $\left(\operatorname{adj}-p 2.96 \times 10^{-5}\right)$ in aged with respect to young ovaries, regardless of parity status (not shown).

The local CXCL1 and CXCL2 synthesis decrease with age, thus promoting infection spread in a mouse model of soft-tissue and skin infection [62]. Age-exacerbated bacterial growth and delayed wound healing in experimental infection have been successfully treated with exogenous CSF3 to enhance neutrophil recruitment [63]. As aging impairs neutrophil and macrophage chemotaxis further than phagocytic or bactericidal capacities [64], our results suggest that increased systemic levels of chemokines measured in aged multiparous mice might help to counteract such an age-dependent impairment of innate immune cell chemotaxis, thus improving endogenous tissue repair. Moreover, the local overexpression of the migration and chemotactic genes Fpr2, S100a8, Sema5a, Fgf13, Gdnf, and Grem 1 (Table 2, Figure 5B) in the aged multiparous ovary would reflect its repertoire of resident leukocyte cells, an idea supported by the analysis of Figure 4E, particularly regarding Fpr2 and S100a8.

Neutrophils, monocytes, and activated macrophages express high levels of S100-calgranulin A (S100a8). This Ca-/Zn-binding protein forms homo- and hetero-dimers (with S100a9), which stimulate the migration of neutrophils to inflammatory sites [65] via tight binding to the CD68 antigen in LPS stimulated macrophages [66]. Interestingly, we found a high $C d 68$ expression in aged relative to young ovaries, irrespective of parity status ( 3.9 fold; adj $p=7.8 \times 10^{-5}$ ). Furthermore, the S100A8/9 heterodimer (calprotectin) is abundant in neutrophils, increases with age in the majority of mouse and human tissues [67], and displays growth-inhibitory and apoptosis-inducing activities on tumor cells and fibroblasts [68]. We observed an increasing trend of the S100a9 transcript level in aged multiparous ovaries, although not reaching statistical significance (raw $p=8.4 \times 10^{-3}$ ). Neutrophil recruitment by S100A9 requires interaction with TLR2 and CXCL2 [69]. Consistently, the serum CXCL2 levels were 
increased in the aged multiparous relative to aged virgin mice (Figure $4 \mathrm{~A}$ ), while our microarray data indicated a Tlr 2 overexpression in aged relative to young ovaries ( 2.3 fold, adj- $p=4 \times 10^{-6}$ ).

Fpr2 codes for a member of the G-protein coupled formyl peptide receptor family that promotes the chemotaxis of immune cells to damaged tissue, thereby preventing inflammation-associated tumorigenesis [70]. Fpr 2 chemoattracts neutrophils and monocytes through chemokines CCL3 and CXCL8 [71]. Consistently, the serum CCL3 levels were higher in the aged multiparous mice in the present study (see Section 3.6). The chemotactic and tissue repair abilities of Fpr2 rely on its ability to sense a wide range of danger (and pathogen)-associated molecular patterns (DAMPs), allowing for neutrophil activation and the subsequent resolution of inflammation [72].

\subsection{Apoptotic Activity in the Aged Multiparous Mouse Ovary}

In aged tissues, apoptosis and senescence may play complementary roles as tumor-suppressor mechanisms [73]. Thus, the positive regulation of apoptosis in the reproductively aged multiparous ovary might act as a safeguard mechanism against pre-neoplasia initiation in a chronic-inflammatory senescent tissue environment by the perpetuation of the SASP. We speculate that the genes associated with cell death (Figure 3B and Table 2) might be involved in the apoptosis of the interstitial cells of a follicular origin, thereby facilitating the action of macrophages. Accordingly, the human early postmenopausal ovaries show apoptotic markers that decay from early to late post-menopause [74], although a parity link has not been suggested yet. During the fertile cycle, cell death is relevant in atresia and luteolysis.

Apoptosis might be also related to the roles of the resident leukocytes of the aged ovary (see Section 3.6). The SASP can lead to chronic deleterious effects because of age-impaired immune function (immune-senescence). Therefore, cell immunity genes, particularly those associated with leukocyte chemotaxis, would promote an efficient removal and processing of apoptotic cells in the aged multiparous ovary. Neutrophil apoptosis is required to activate the phagocytic capacity of macrophages, thereby resolving inflammation [75]. In contrast, this process would be impaired in the aged virgin ovary, thus leading to an excessive accumulation of incompletely digested cell debris in the form of lipofuscin, as we recently reported [22]. Ovarian lipofuscin might be the consequence of an overload of atretic material during reproductive aging, which is not properly cleared, thus accumulating because lysosomal and/or proteasomal dysfunction by age-induced cell damage, as has been described in other tissues [76].

\section{Conclusions}

Here, we applied an integrative analysis (GO, GSEA, PPI networks, and Ref-DIC) to the ovarian transcriptome and systemic chemokine profiles observed in the naturally aged C57BL/6 mouse ovary so as to gain insight into the molecular basis of OC risk reduction by parity history. The mice were maintained in multiparous versus virgin regimens until estropausal age, equivalent to early post-menopause in women. Regardless of parity status, the aged ovary expressed a high content of genes involved in immune/inflammatory response, cell adhesion, TNF synthesis, proteolysis, and wound healing, thus reflecting a low-grade chronic inflammation due to endogenous tissue damage, which is characteristic of SASP. Leukocyte markers, including macrophage, neutrophil, lymphocyte, and mast cell transcripts, were also detected in the aged ovary. More importantly, aged multiparous ovaries showed a higher residual content of primordial and total follicles, relative to aged virgin ovaries. This finding agreed with the higher transcript levels of the 26 DEGs-out of the 65 total-with reported evidence of the roles in the homeostasis of oocytes, follicles, and the ovary, particularly genes preventing the exhaustion of the primordial follicle pool. The remaining DEGs were enriched in innate immunity mainly related to neutrophil and macrophage chemotaxis, while their expression profile resembled the circulating levels of the CXCL1, CXCL2, CXCL5, CSF3, and CCL3 chemokines implicated in the repair of endogenous tissue damage. We conclude that the aged multiparous ovary retains a remnant follicle reserve that evades either maturation or atresia, probably 
due to the combined action of paracrine Tgf/Bmp antagonists and the modulation of Fshr-Foxo1 signaling. Coincident with this residual follicular reserve, past parity would enhance the immune-surveillance capacity of resident ovarian macrophages and neutrophils by improving their phagocytic ability on apoptotic atretic cells, thereby minimizing the deleterious effects of SASP. In summary, the observed protection of pregnancy (or progestin-induced anovulation) against ovarian neoplasia may be regarded as a long-term "imprint", leading to persistent remnant follicles with concomitant robust innate immunity in the aged multiparous ovary. How this imprint is generated during a woman's fertile life and overcomes the effects of ovarian aging it remains to be investigated.

Supplementary Materials: The following are available online at http:/www.mdpi.com/2218-273X/10/1/113/s1. Supplementary File 1: Excel spreadsheet containing the list of 177 DEGs with $\log _{2}$ FC results and gene identifiers. Supplementary File 2: Methods in detail.

Author Contributions: Conceptualization, U.U.; methodology, U.U., C.C., M.N., L.L., S.S., E.A., J.I.P., and S.A.; software, E.A. and J.I.P.; formal analysis, U.U., M.N., L.L., and S.A.; investigation, U.U., C.C., M.N., L.L., S.S., and S.A.; data curation, U.U., E.A., and J.I.P.; writing (original draft preparation), U.U.; writing (review and editing), U.U.; project administration, U.U.; funding acquisition, U.U., A.E., J.I.P. All authors have read and agreed to the published version of the manuscript.

Funding: This work was funded by FONDECYT, grant number 1130292, Ministry of Education, Chile; and in part by the Intramural Research Program of the Center for Information Technology, National Institutes of Health (ZIA CT000260).

Acknowledgments: Thanks to Manuel Suarez and Carola Perez for assistance in animal care, and Isabel Castro, Julieta González, and Nevenka Juretic for advice in gene expression assays. We acknowledge support from VID-Universidad de Chile (AYV0210218) to disseminate part of these data at the IX International Congress on Human Genetics (Barranquilla, Colombia, September 2018).

Conflicts of Interest: The authors declare no conflict of interest. The funders had no role in the design of the study; in the collection, analyses, or interpretation of data; in the writing of the manuscript; or in the decision to publish the results.

\section{References}

1. Lopez-Otin, C.; Blasco, M.A.; Partridge, L.; Serrano, M.; Kroemer, G. The hallmarks of aging. Cell 2013, 153, 1194-1217. [CrossRef] [PubMed]

2. Broekmans, F.J.; Soules, M.R.; Fauser, B.C. Ovarian aging: Mechanisms and clinical consequences. Endocr. Rev. 2009, 30, 465-493. [CrossRef] [PubMed]

3. Van der Hyden, B.C. Loss of ovarian function and the risk of ovarian cancer. Cell Tissue Res. 2005, 322, 117-124. [CrossRef]

4. Smith, E.R.; Xu, X.X. Ovarian ageing, follicle depletion, and cancer: A hypothesis for the aetiology of epithelial ovarian cancer involving follicle depletion. Lancet Oncol. 2008, 9, 1108-1111. [CrossRef]

5. Wang, Y.; Cai, K.Q.; Smith, E.R.; Yeasky, T.M.; Moore, R.; Ganjei-Azar, P.; Klein-Szanto, A.J.; Godwin, A.K.; Hamilton, T.C.; Xu, X.X. Follicle Depletion Provides a Permissive Environment for Ovarian Carcinogenesis. Mol. Cell. Biol. 2016, 36, 2418-2430. [CrossRef] [PubMed]

6. Klotz, D.M.; Wimberger, P. Cells of origin of ovarian cancer: Ovarian surface epithelium or fallopian tube? Arch. Gynecol. Obstet. 2017, 296, 1055-1062. [CrossRef]

7. Cai, K.Q.; Wang, Y.; Smith, E.R.; Smedberg, J.L.; Yang, D.H.; Yang, W.L.; Xu, X.X. Global deletion of Trp53 reverts ovarian tumor phenotype of the germ cell-deficient white spotting variant (Wv) mice. Neoplasia 2015, 17, 89-100. [CrossRef]

8. Smith, E.R.; Wang, Y.; Xu, X.X. Development of a mouse model of menopausal ovarian cancer. Front. Oncol. 2014, 4, 36. [CrossRef]

9. Scully, R.E. Pathology of ovarian cancer precursors. J. Cell. Biochem. 1995, 59, 208-218. [CrossRef]

10. Banet, N.; Kurman, R.J. Two types of ovarian cortical inclusion cysts: Proposed origin and possible role in ovarian serous carcinogenesis. Int. J. Gynecol. Pathol. 2015, 34, 3-8. [CrossRef]

11. Hunn, J.; Rodriguez, G.C. Ovarian cancer: Etiology, risk factors, and epidemiology. Clin. Obstet. Gynecol. 2012, 55, 3-23. [CrossRef]

12. Fougère, B.; Boulanger, E.; Nourhashémi, F.; Guyonnet, S.; Cesari, M. Chronic Inflammation: Accelerator of Biological Aging. J. Gerontol. A Biol. Sci. Med. Sci. 2017, 72, 1218-1225. [CrossRef] [PubMed] 
13. Faddy, M.J.; Gosden, R.G. A model conforming the decline in follicle numbers to the age of menopause in women. Hum. Reprod. 1996, 11, 1484-1486. [CrossRef] [PubMed]

14. Moini, A.; Hedayatshodeh, M.; Hosseini, R.; Rastad, H. Association between parity and ovarian reserve in reproductive age women. Eur. J. Obstet. Gynecol. Reprod. Biol. 2016, 207, 184-187. [CrossRef] [PubMed]

15. Makowski, L.; Zhou, C.; Zhong, Y.; Kuan, P.F.; Fan, C.; Sampey, B.P.; Difurio, M.; Bae-Jump, V.L. Obesity increases tumor aggressiveness in a genetically engineered mouse model of serous ovarian cancer. Gynecol. Oncol. 2014, 133, 90-97. [CrossRef]

16. Jia, D.; Nagaoka, Y.; Katsumata, M.; Orsulic, S. Inflammation is a key contributor to ovarian cancer cell seeding. Sci. Rep. 2018, 8, 12394. [CrossRef]

17. Li, C.; Course, M.M.; McNeish, I.A.; Drescher, C.W.; Valdmanis, P.N.; Lieber, A. Prophylactic in vivo hematopoietic stem cell gene therapy with an immune checkpoint inhibitor reverses tumor growth in syngeneic mouse tumor models. Cancer Res. 2019. [CrossRef]

18. Urzua, U.; Chacon, C.; Lizama, L.; Sarmiento, S.; Villalobos, P.; Kroxato, B.; Marcelain, K.; Gonzalez, M.J. Parity History Determines a Systemic Inflammatory Response to Spread of Ovarian Cancer in Naturally Aged Mice. Aging Dis. 2017, 8, 546-557. [CrossRef]

19. Griffin, J.; Emery, B.R.; Huang, I.; Peterson, C.M.; Carrell, D.T. Comparative analysis of follicle morphology and oocyte diameter in four mammalian species (mouse, hamster, pig, and human). J. Exp. Clin. Assist. Reprod. 2006, 3, 2. [CrossRef]

20. Sharov, A.A.; Falco, G.; Piao, Y.; Poosala, S.; Becker, K.G.; Zonderman, A.B.; Longo, D.L.; Schlessinger, D.; Ko, M.S. Effects of aging and calorie restriction on the global gene expression profiles of mouse testis and ovary. BMC Biol. 2008, 6, 24. [CrossRef]

21. Rozen, S.; Skaletsky, H. Primer3 on the WWW for general users and for biologist programmers. Methods Mol. Biol. 2000, 132, 365-386. [PubMed]

22. Urzua, U.; Chacon, C.; Espinoza, R.; Martínez, S.; Hernandez, N. Parity-Dependent Hemosiderin and Lipofuscin Accumulation in the Reproductively Aged Mouse Ovary. Anal. Cell. Pathol. 2018, 2018, 1289103. [CrossRef] [PubMed]

23. Malaquin, N.; Martinez, A.; Rodier, F. Keeping the senescence secretome under control: Molecular reins on the senescence-associated secretory phenotype. Exp. Gerontol. 2016, 82, 39-49. [CrossRef] [PubMed]

24. Pangas, S.A.; Li, X.; Umans, L.; Zwijsen, A.; Huylebroeck, D.; Gutierrez, C.; Wang, D.; Martin, J.F.; Jamin, S.P.; Behringer, R.R.; et al. Conditional deletion of Smad1 and Smad5 in somatic cells of male and female gonads leads to metastatic tumor development in mice. Mol. Cell. Biol. 2008, 28, 248-257. [CrossRef] [PubMed]

25. Lee, K.Y.; Jeong, J.W.; Wang, J.; Ma, L.; Martin, J.F.; Tsai, S.Y.; Lydon, J.P.; DeMayo, F.J. Bmp2 is critical for the murine uterine decidual response. Mol. Cell. Biol. 2007, 27, 5468-5478. [CrossRef] [PubMed]

26. Finco, I.; LaPensee, C.R.; Krill, K.T.; Hammer, G.D. Hedgehog signaling and steroidogenesis. Annu. Rev. Physiol. 2015, 77, 105-129. [CrossRef]

27. Wu, R.; Van der Hoek, K.H.; Ryan, N.K.; Norman, R.J.; Robker, R.L. Macrophage contributions to ovarian function. Hum. Reprod. Update 2004, 10, 119-133. [CrossRef]

28. Turner, E.C.; Hughes, J.; Wilson, H.; Clay, M.; Mylonas, K.J.; Kipari, T.; Duncan, W.C.; Fraser, H.M. Conditional ablation of macrophages disrupts ovarian vasculature. Reproduction 2011, 141, 821-831. [CrossRef]

29. Pepe, G.; Locati, M.; Della Torre, S.; Mornata, F.; Cignarella, A.; Maggi, A.; Vegeto, E. The estrogen-macrophage interplay in the homeostasis of the female reproductive tract. Hum. Reprod. Update 2018, 24, 652-672. [CrossRef]

30. Hijikata, A.; Kitamura, H.; Kimura, Y.; Yokoyama, R.; Aiba, Y.; Bao, Y.; Fujita, S.; Hase, K.; Hori, S.; Ishii, Y.; et al. Construction of an open-access database that integrates cross-reference information from the transcriptome and proteome of immune cells. Bioinformatics 2007, 23, 2934-2941. [CrossRef]

31. Ignacio, R.M.C.; Lee, E.S.; Son, D.S. Potential Roles of Innate Immune Chemokine and Cytokine Network on Lipopolysaccharide-Based Therapeutic Approach in Ovarian Cancer. Immune Netw. 2019, 19, e22. [CrossRef]

32. Gougeon, A.; Ecochard, R.; Thalabard, J.C. Age-related changes of the population of human ovarian follicles: Increase in the disappearance rate of non-growing and early-growing follicles in aging women. Biol. Reprod. 1994, 50, 653-663. [CrossRef] [PubMed]

33. Pangas, S.A. Regulation of the ovarian reserve by members of the transforming growth factor beta family. Mol. Reprod. Dev. 2012, 79, 666-679. [CrossRef] 
34. Knight, P.G.; Satchell, L.; Glister, C. Intra-ovarian roles of activins and inhibins. Mol. Cell. Endocrinol. 2012, 359, 53-65. [CrossRef] [PubMed]

35. Brodowska, A.; Laszczyńska, M.; Brodowski, J.; Masiuk, M.; Starczewski, A. Analysis of pituitary gonadotropin concentration in blood serum and immunolocalization and immunoexpression of follicle stimulating hormone and luteinising hormone receptors in ovaries of postmenopausal women. Histol. Histopathol. 2012, 27, 241-248.

36. Brodowska, A.; Brodowski, J.; Laszczyńska, M.; Słuczanowska-Głąbowska, S.; Rumianowski, B.; Rotter, I.; Starczewski, A.; Ratajczak, M.Z. Immunoexpression of aromatase cytochrome P450 and 17 $\beta$-hydroxysteroid dehydrogenase in women's ovaries after menopause. J. Ovarian Res. 2014, 7, 52. [CrossRef]

37. Jabara, S.; Christenson, L.K.; Wang, C.Y.; McAllister, J.M.; Javitt, N.B.; Dunaif, A.; Strauss, J.F., 3rd. Stromal cells of the human postmenopausal ovary display a distinctive biochemical and molecular phenotype. J. Clin. Endocrinol. Metab. 2003, 88, 484-492. [CrossRef]

38. Reame, N.E.; Lukacs, J.L.; Olton, P.; Ansbacher, R.; Padmanabhan, V. Differential effects of aging on activin A and its binding protein, follistatin, across the menopause transition. Fertil. Steril. 2007, 88, 1003-1005. [CrossRef] [PubMed]

39. Wang, Z.; Niu, W.; Wang, Y.; Teng, Z.; Wen, J.; Xia, G.; Wang, C. Follistatin288 Regulates Germ Cell Cyst Breakdown and Primordial Follicle Assembly in the Mouse Ovary. PLoS ONE 2015, 10, e129643. [CrossRef] [PubMed]

40. Sanfins, A.; Rodrigues, P.; Albertini, D.F. GDF-9 and BMP-15 direct the follicle symphony. J. Assist. Reprod. Genet. 2018, 35, 1741-1750. [CrossRef] [PubMed]

41. von Schönfeldt, V.; Chandolia, R.; Ochsenkühn, R.; Nieschlag, E.; Kiesel, L.; Sonntag, B. FSH prevents depletion of the resting follicle pool by promoting follicular number and morphology in fresh and cryopreserved primate ovarian tissues following xenografting. Reprod. Biol. Endocrinol. 2012, 10, 98. [CrossRef] [PubMed]

42. Yang, Y.; Chen, J.; Wu, H.; Pei, X.; Chang, Q.; Ma, W.; Ma, H.; Hei, C.; Zheng, X.; Cai, Y.; et al. The Increased Expression of Connexin and VEGF in Mouse Ovarian Tissue Vitrification by Follicle Stimulating Hormone. BioMed Res. Int. 2015, 2015, 397264. [CrossRef]

43. Adashi, E.Y. The climacteric ovary as a functional gonadotropin-driven androgen-producing gland. Fertil. Steril. 1994, 62, 20-27. [CrossRef]

44. Brodowski, J.; Brodowska, A.; Laszczyńska, M.; Chlubek, D.; Starczewski, A. Hormone concentrations in the homogenates of ovarian tissue and blood serum in postmenopausal women not using hormone therapy. Gynecol. Endocrinol. 2012, 28, 396-399. [CrossRef] [PubMed]

45. Fogle, R.H.; Stanczyk, F.Z.; Zhang, X.; Paulson, R.J. Ovarian androgen production in postmenopausal women. J. Clin. Endocrinol. Metab. 2007, 92, 3040-3043. [CrossRef] [PubMed]

46. Hassa, H.; Aydin, Y.; Ozatik, O.; Erol, K.; Ozatik, Y. Effects of dehydroepiandrosterone (DHEA) on follicular dynamics in a diminished ovarian reserve in vivo model. Syst. Biol. Reprod. Med. 2015, 61, 117-121. [CrossRef]

47. Martins, R.; Lithgow, G.J.; Link, W. Long live FOXO: Unraveling the role of FOXO proteins in aging and longevity. Aging Cell 2016, 15, 196-207. [CrossRef]

48. Herndon, M.K.; Law, N.C.; Donaubauer, E.M.; Kyriss, B.; Hunzicker-Dunn, M. Forkhead box O member FOXO1 regulates the majority of follicle-stimulating hormone responsive genes in ovarian granulosa cells. Mol. Cell. Endocrinol. 2016, 434, 116-126. [CrossRef]

49. Shi, F.; LaPolt, P.S. Relationship between FoxO1 protein levels and follicular development, atresia, and luteinization in the rat ovary. J. Endocrinol. 2003, 179, 195-203. [CrossRef]

50. Shen, M.; Liu, Z.; Li, B.; Teng, Y.; Zhang, J.; Tang, Y.; Sun, S.C.; Liu, H. Involvement of FoxO1 in the effects of follicle-stimulating hormone on inhibition of apoptosis in mouse granulosa cells. Cell Death Dis. 2014, 5, e1475. [CrossRef]

51. Shen, M.; Jiang, Y.; Guan, Z.; Cao, Y.; Li, L.; Liu, H.; Sun, S.C. Protective mechanism of FSH against oxidative damage in mouse ovarian granulosa cells by repressing autophagy. Autophagy 2017, 13, 1364-1385. [CrossRef] [PubMed]

52. Liu, Z.; Rudd, M.D.; Hernandez-Gonzalez, I.; Gonzalez-Robayna, I.; Fan, H.Y.; Zeleznik, A.J.; Richards, J.S. FSH and FOXO1 regulate genes in the sterol/steroid and lipid biosynthetic pathways in granulosa cells. Mol. Endocrinol. 2009, 23, 649-661. [CrossRef] [PubMed] 
53. Bertolin, K.; Gossen, J.; Schoonjans, K.; Murphy, B.D. The orphan nuclear receptor Nr5a2 is essential for luteinization in the female mouse ovary. Endocrinology 2014, 155, 1931-1943. [CrossRef] [PubMed]

54. Nechamen, C.A.; Thomas, R.M.; Dias, J.A. APPL1, APPL2, Akt2 and FOXO1a interact with FSHR in a potential signaling complex. Mol. Cell. Endocrinol. 2007, 260-262, 93-99. [CrossRef]

55. Sun, X.F.; Sun, X.H.; Cheng, S.F.; Wang, J.J.; Feng, Y.N.; Zhao, Y.; Yin, S.; Hou, Z.M.; Shen, W.; Zhang, X.F. Interaction of the transforming growth factor- $\beta$ and Notch signaling pathways in the regulation of granulosa cell proliferation. Reprod. Fertil. Dev. 2016, 28, 1873-1881. [CrossRef]

56. Vanorny, D.A.; Prasasya, R.D.; Chalpe, A.J.; Kilen, S.M.; Mayo, K.E. Notch signaling regulates ovarian follicle formation and coordinates follicular growth. Mol. Endocrinol. 2014, 28, 499-511. [CrossRef]

57. Balistreri, C.R.; Madonna, R.; Melino, G.; Caruso, C. The emerging role of Notch pathway in ageing: Focus on the related mechanisms in age-related diseases. Ageing Res. Rev. 2016, 29, 50-65. [CrossRef]

58. Carlock, C.; Wu, J.; Zhou, C.; Ross, A.; Adams, H.; Lou, Y. Ovarian phagocyte subsets and their distinct tissue distribution patterns. Reproduction 2013, 146, 491-500. [CrossRef]

59. Rajarathnam, K.; Schnoor, M.; Richardson, R.M.; Rajagopal, S. How do chemokines navigate neutrophils to the target site: Dissecting the structural mechanisms and signaling pathways. Cell Signal. 2019, 54, 69-80. [CrossRef]

60. Hol, J.; Wilhelmsen, L.; Haraldsen, G. The murine IL-8 homologues KC, MIP-2, and LIX are found in endothelial cytoplasmic granules but not in Weibel-Palade bodies. J. Leukoc. Biol. 2010, 87, 501-508. [CrossRef]

61. Luo, W.; Salih, S.M.; Bormann, C.L.; Wiltbank, M.C. Induction of chemokines and prostaglandin synthesis pathways in luteinized human granulosa cells: Potential role of luteotropin withdrawal and prostaglandin F2 $\alpha$ in regression of the human corpus luteum. Reprod. Biol. 2015, 15, 247-256. [CrossRef] [PubMed]

62. Tseng, C.W.; Kyme, P.A.; Arruda, A.; Ramanujan, V.K.; Tawackoli, W.; Liu, G.Y. Innate immune dysfunctions in aged mice facilitate the systemic dissemination of methicillin-resistant S. aureus. PLoS ONE 2012, 7, e41454. [CrossRef] [PubMed]

63. Brubaker, A.L.; Kovacs, E.J. G-CSF enhances resolution of Staphylococcus aureus wound infection in an age-dependent manner. Shock 2013, 40, 327-333. [CrossRef] [PubMed]

64. Brubaker, A.L.; Rendon, J.L.; Ramirez, L.; Choudhry, M.A.; Kovacs, E.J. Reduced neutrophil chemotaxis and infiltration contributes to delayed resolution of cutaneous wound infection with advanced age. J. Immunol. 2013, 190, 1746-1757. [CrossRef]

65. Ryckman, C.; Vandal, K.; Rouleau, P.; Talbot, M.; Tessier, P.A. Proinflammatory activities of S100: Proteins S100A8, S100A9, and S100A8/A9 induce neutrophil chemotaxis and adhesion. J. Immunol. 2003, 170, 3233-3242. [CrossRef]

66. Okada, K.; Arai, S.; Itoh, H.; Adachi, S.; Hayashida, M.; Nakase, H.; Ikemoto, M. CD68 on rat macrophages binds tightly to S100A8 and S100A9 and helps to regulate the cells' immune functions. J. Leukoc. Biol. 2016, 100, 1093-1104. [CrossRef]

67. Swindell, W.R.; Johnston, A.; Xing, X.; Little, A.; Robichaud, P.; Voorhees, J.J.; Fisher, G.; Gudjonsson, J.E. Robust shifts in S100a9 expression with aging: A novel mechanism for chronic inflammation. Sci. Rep. 2013, 3, 1215. [CrossRef]

68. Yui, S.; Nakatani, Y.; Mikami, M. Calprotectin (S100A8/S100A9), an inflammatory protein complex from neutrophils with a broad apoptosis-inducing activity. Biol. Pharm. Bull. 2003, 26, 753-760. [CrossRef]

69. Moles, A.; Murphy, L.; Wilson, C.L.; Chakraborty, J.B.; Fox, C.; Park, E.J.; Mann, J.; Oakley, F.; Howarth, R.; Brain, J.; et al. A TLR2/S100A9/CXCL-2 signaling network is necessary for neutrophil recruitment in acute and chronic liver injury in the mouse. J. Hepatol. 2014, 60, 782-791. [CrossRef]

70. Chen, K.; Bao, Z.; Gong, W.; Tang, P.; Yoshimura, T.; Wang, J.M. Regulation of inflammation by members of the formyl-peptide receptor family. J. Autoimmun. 2017, 85, 64-77. [CrossRef]

71. De Buck, M.; Gouwy, M.; Berghmans, N.; Opdenakker, G.; Proost, P.; Struyf, S.; Van Damme, J. COOH-terminal SAA1 peptides fail to induce chemokines but synergize with CXCL8 and CCL3 to recruit leukocytes via FPR2. Blood 2018, 131, 439-449. [CrossRef] [PubMed]

72. Filep, J.G.; Sekheri, M.; El Kebir, D. Targeting formyl peptide receptors to facilitate the resolution of inflammation. Eur. J. Pharmacol. 2018, 833, 339-348. [CrossRef] [PubMed]

73. Cerella, C.; Grandjenette, C.; Dicato, M.; Diederich, M. Roles of Apoptosis and Cellular Senescence in Cancer and Aging. Curr. Drug Targets 2016, 17, 405-415. [CrossRef] [PubMed] 
74. Brodowska, A.; Laszczyńska, M.; Starczewski, A. Apoptosis in ovarian cells in postmenopausal women. Folia Histochem. Cytobiol. 2007, 45, 99-105. [PubMed]

75. Thieblemont, N.; Witko-Sarsat, V.; Ariel, A. Regulation of macrophage activation by proteins expressed on apoptotic neutrophils: Subversion towards autoimmunity by proteinase 3. Eur. J. Clin. Investig. 2018, 48 (Suppl. 2), e12990. [CrossRef] [PubMed]

76. Jung, T.; Bader, N.; Grune, T. Lipofuscin: Formation, distribution, and metabolic consequences. Ann. N. Y. Acad. Sci. 2007, 1119, 97-111. [CrossRef] [PubMed]

(C) 2020 by the authors. Licensee MDPI, Basel, Switzerland. This article is an open access article distributed under the terms and conditions of the Creative Commons Attribution (CC BY) license (http://creativecommons.org/licenses/by/4.0/). 